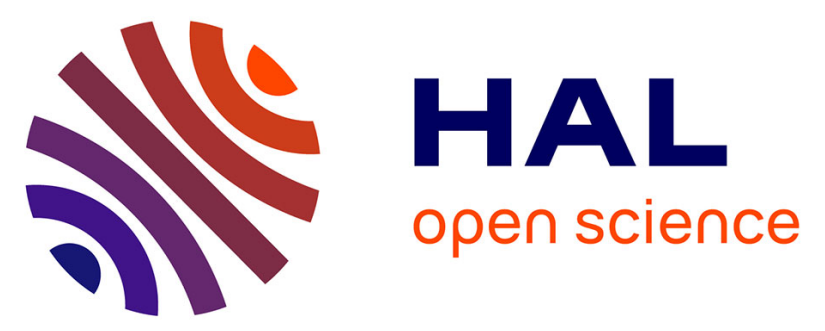

\title{
Micron-Sized Main-Chain Liquid Crystalline Elastomer Actuators with Ultralarge Amplitude Contractions
}

Hong Yang, Axel Buguin, Jean-Marie Taulemesse, Kosuke Kaneko, Stéphane Méry, Anne Bergeret, Patrick Keller

\section{- To cite this version:}

Hong Yang, Axel Buguin, Jean-Marie Taulemesse, Kosuke Kaneko, Stéphane Méry, et al.. MicronSized Main-Chain Liquid Crystalline Elastomer Actuators with Ultralarge Amplitude Contractions. Journal of the American Chemical Society, 2009, 131 (41), pp.15000-15004. 10.1021/ja905363f . hal03247454

\section{HAL Id: hal-03247454 https://hal.mines-ales.fr/hal-03247454}

Submitted on 3 Jun 2021

HAL is a multi-disciplinary open access archive for the deposit and dissemination of scientific research documents, whether they are published or not. The documents may come from teaching and research institutions in France or abroad, or from public or private research centers.
L'archive ouverte pluridisciplinaire HAL, est destinée au dépôt et à la diffusion de documents scientifiques de niveau recherche, publiés ou non, émanant des établissements d'enseignement et de recherche français ou étrangers, des laboratoires publics ou privés. 


\title{
Micron-Sized Main-Chain Liquid Crystalline Elastomer Actuators with Ultralarge Amplitude Contractions
}

\author{
Hong Yang, ${ }^{\dagger}$ Axel Buguin, ${ }^{\dagger}$ Jean-Marie Taulemesse, ${ }^{\ddagger}$ Kosuke Kaneko,,$\$$ \\ Stéphane Méry, ${ }^{\S}$ Anne Bergeret, ${ }^{\ddagger}$ and Patrick Keller ${ }^{*, \dagger}$ \\ Institut Curie, Centre de Recherche, CNRS UMR 168, Université Pierre et Marie Curie, 26 rue \\ d'Ulm 75248 Paris cedex 05, France, Centre des Matériaux de Grande Diffusion, Ecole des \\ Mines d'Alès, 6 avenue de Clavières 30319 Alès cedex, France, and IPCMS, UMR 7504 \\ CNRS-Unistra, 23 rue du Loess BP 4367034 Strasbourg cedex 02, France
}

\begin{abstract}
Responsive surfaces composed of cylindrical or square micrometer-sized thermoresponsive pillars made of thiol-ene nematic main-chain liquid crystalline elastomers (LCEs) are produced by replica molding. The individual pillars behave as microactuators, showing ultralarge and reversible contractions of around $300-400 \%$ at the nematic to isotropic phase transition. The nematic main-chain LCE microactuators described here present contractions as large as the best macroscopic systems reported in the literature. Moreover, the contraction observed for this new system outperforms the best values already reported for other LCE microsystems.
\end{abstract}

\section{Introduction}

Materials scientists are increasingly turning to nature as a source of inspiration to develop new devices mimicking the structure and function of real biological systems. ${ }^{1-3}$ Research regularly points out that many phenomena encountered in nature, such as the self-cleaning properties of lotus and rice leaves, ${ }^{4}$ the "sticky feet" of geckos, ${ }^{5}$ the vivid colors of the butterfly wings, ${ }^{6}$ or the drag-reducing surface of shark $\operatorname{skin}^{7}$ to name a few, are related to the specific micro and nanostructures of the involved surfaces. The search for smart materials, also called actuators or artificial muscles, that respond to external stimuli with changes in shape or size has recently attracted considerable attention from the material research community. ${ }^{8,9}$ Polymers play a leading role in the domain of smart materials because they provide several key advantages: low manufacturing cost, high processability, flexibility, relatively low weight density, ${ }^{10,11}$

\footnotetext{
$\dagger$ Institut Curie.

$\doteqdot$ Ecole des Mines d'Alès.

$\S$ IPCMS.

(1) Sanchez, C.; Arribart, H.; Giraud Guille, M. M. Nat. Mater. 2005, 4, 277-288.

(2) Le Duc, P. R.; Robinson, D. N. Adv. Mater. 2007, 19, 3761-3770.

(3) Xia, F.; Jiang, L. Adv. Mater. 2008, 20, 2842-2858.

(4) Koch, K.; Bhushan, B.; Barthlott, W. Soft Matter 2008, 4, 1943-1963.

(5) Murphy, M. P.; Kim, S.; Sitti, M. ACS Appl. Mater. Interfaces 2009, $1,849-855$.

(6) Sato, O.; Kubo, S.; Gu, Z.-Z. Acc. Chem. Res. 2009, 42, 1-10.

(7) Bushnell, D. M.; Moore, K. J. Annu. Rev. Fluid Mech. 1991, 23, 6579.

(8) Madden, J. D. W.; Vandersteeg, N. A.; Anquetil, P. A.; Madden, P. G. A.; Takshi, A.; Pytel, R. Z.; Lafontaine, S. R.; Wieringa, P. A.; Hunter, I. W. IEEE J. Oceanic Eng. 2004, 29, 706-728.

(9) Hannaford, B.; Jaax, K.; Klute, G. Autonomus Robots 2001, 11, 267 272.

(10) Electroactive Polymer Actuators as Artificial Muscles: Reality, Potential and Challenges, 2nd ed.; Bar-Cohen, Y., Ed.; SPIE-The International Society of Optical Engineering: Bellington, WA, 2004.
}

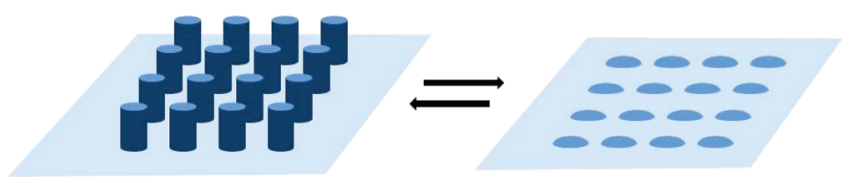

Figure 1. Responsive surface with a stimuli-driven roughness change.

etc. Combining these two domains, smart materials and solid surfaces with special properties (low friction, specific optical properties, etc.), could lead to the development of new responsive surfaces with tunable micro/nanostructures, controlled by external stimuli. To produce responsive surfaces such as the one pictured in Figure 1, the surface must be covered with micro (or nano) actuators, contracting along their long axis. Moreover, the contraction must be large enough so that the roughness of the surface will be substantially changed.

Nematic liquid crystalline elastomers (LCEs) ${ }^{12}$ appear as very promising candidates to build such responsive surfaces. Nematic LCEs are soft polymeric actuators that can contract reversibly under the influence of various stimuli such as a change in temperature (thermomechanical effect) ${ }^{12,13}$ or UV irradiation (photomechanical effect). ${ }^{12,14}$ The motor for contraction is the conformational change occurring at the level of the polymer backbone at the nematic to isotropic phase transition: due to the influence of the nematic order on the polymer chain, the backbone adopts an anisotropic conformation. When the nematic

(11) Mirfahrai, T.; Madden, J. D. W.; Baughman, R. H. Mater. Today 2007, 10, 30-38.

(12) Warner, M.; Terentjev, E. M. Liquid Crystal Elastomers; Oxford University Press: New York, 2007.

(13) Li, M.-H.; Keller, P. Philos. Trans. R. Soc. Lond. A 2006, 364, $2763-$ 2777 , and references therein.

(14) Ikeda, T.; Mamiya, J.-I.; Yu, Y. Angew. Chem., Int. Ed. 2007, 46, 506-528, and references therein. 
order is destroyed, that is, at the nematic to isotropic phase transition, the polymer backbone returns to a random coil conformation typical of a melted polymer chain. In a monodomain nematic single crystal elastomer, ${ }^{15}$ in which all the polymer chains are, on average, parallel to each other and crosslinked, this molecular level shape change translates to the macroscopic sample. This coupling between nematic order and average macromolecular shape is the strongest for main-chain liquid crystalline polymers (LCPs) in which the mesogenic groups are incorporated into the polymer chains. ${ }^{16}$

Several LCE-based artificial muscles have been described over the last 10 years, ${ }^{12-14,17}$ although De Gennes introduced the fundamental theoretical basis for LCEs as early as $1969 .{ }^{18}$ Some years ago, using a soft lithography technique called replica molding, we succeeded in creating micrometer-sized responsive pillars made of LCEs. ${ }^{19}$ However, due to the type of LCE used, a side-on LCE, a relatively small contraction was observed, around $35-40 \%$. Clearly, to achieve the kind of surface modification presented in Figure 1, we need to use main-chain LCEs, for which contractions of 300-500\% have been reported in macroscopic samples. ${ }^{20-26}$ However, no micrometer or nanosized main-chain LCE actuators have been developed, the limitation being the synthetic scheme, which normally requires a two-step cross-linking procedure under mechanical stress, as originally described by Finkelmann. ${ }^{15}$ We have now succeeded in creating, for the first time, micrometer-sized pillars made of main-chain LCE by photopolymerization, using a thiol-ene approach. The micrometer-sized actuators undergo an ultralarge and reversible contraction of around $400 \%$ when heated at a temperature close to the nematic to isotropic phase transition of the LCE.

\section{Results and Discussion}

Main-chain LCPs have been intensely studied in the past because they present potentially interesting mechanical properties. $^{27}$ However, most of these polymers were prepared by polycondensation reactions in solution or in the melt to give polyesters, polyamides, polyisocyanates, etc. The system we have developed to make micrometer-sized aligned nematic LCE actuators ${ }^{19}$ relies on the orientation, via a magnetic field, of a nematic mixture containing a monomer, a cross-linker and a photoinitiator, followed by a photopolymerization process to give the aligned nematic elastomer in one step. To apply this strategy to the preparation of main-chain LCE pillars, we needed

(15) Küpfer, J.; Finkelmann, H. Makromol. Chem. Rapid Commun. 1991, 12, 717-726.

(16) Cotton, J.-P.; Hardouin, F. Prog. Polym. Sci. 1997, 22, 795-828.

(17) Xie, P.; Zhang, R. J. Mater. Chem. 2005, 15, 2529-2550, and references therein.

(18) de Gennes, P.-G. Phys. Lett. A 1969, 28A, 725-726.

(19) Buguin, A.; Li, M.-H.; Silberzan, P.; Ladoux, B.; Keller, P. J. Am. Chem. Soc. 2006, 128, 1088-1089.

(20) Bergmann, G. H. F.; Finkelmann, H.; Percec, V.; Zhao, M. Macromol. Rapid Commun. 1997, 18, 353-360.

(21) Donnio, B.; Wermter, H.; Finkelmann, H. Macromolecules 2000, 33 , 7724-7729.

(22) Wermter, H.; Finkelmann, H. e-Polym. 2001, 013.

(23) Tajbakhsh, A. R.; Terentjev, E. M. Eur. Phys. J. E. 2001, 6, 181188.

(24) Ahir, S. V.; Tajbakhsh, A. R.; Terentjev, E. M. Adv. Funct. Mater. 2006, 16, 556-560.

(25) Bispo, M.; Guillon, D.; Donnio, B.; Finkelmann, H. Macromolecules 2008, 41, 3098-3108.

(26) Krause, S.; Zander, F.; Bergmann, G.; Brandt, H.; Wertmer, H.; Finkelmann, H. C. R. Chimie 2009, 12, 85-104.

(27) Dobb, M. G.; McIntyre, J. E. Adv. Polym. Sci. 1984, 60/61, 61-98, and references therein.
Scheme 1. Synthesis of the Tetra Functional Crosslinker 2
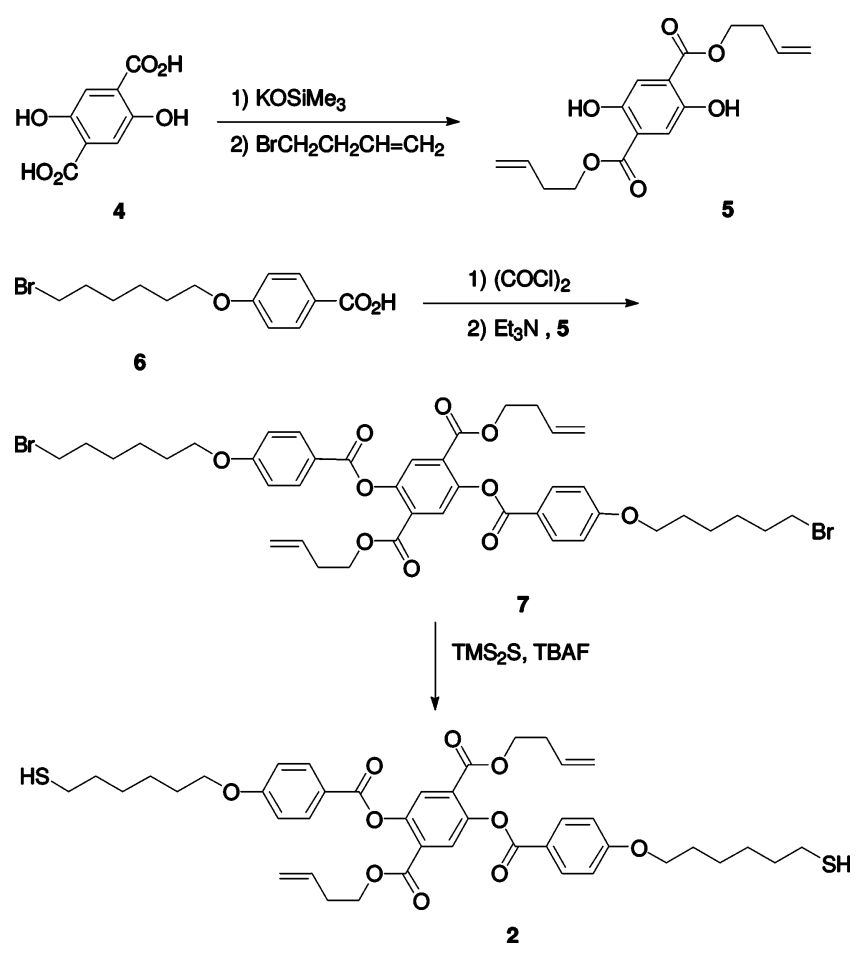

to develop a system that could be prepared via photopolymerization. The photoinduced addition of thiols on olefins (the socalled thiol-ene photopolymerization) is a well-known reaction for nonmesomorphic systems, resulting in linear polymers. ${ }^{28}$ The synthesis and photopolymerization of mesomorphic compounds containing vinyl and mercapto groups to give mainchain LCP has been previously described by Lub et al. ${ }^{29-33}$ but did not receive much attention. Moreover, thiol-ene polymers/elastomers have never been used in the context of LCE actuators. We prepared a new nematic thiol-ene monomer 1 using the synthetic procedure of Lub et al., ${ }^{33}$ and the new tetra functional mesogenic cross-linker 2 by the route described in Scheme 1.

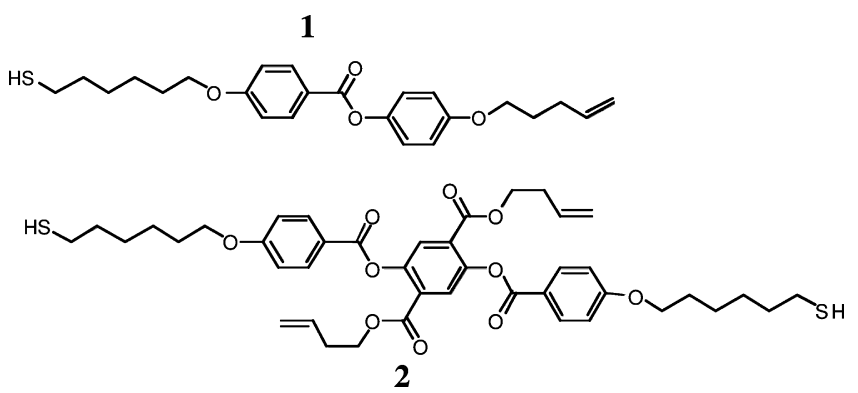

(28) Hoyle, C. E.; Lee, T. Y.; Roper, T. J. Polym. Sci., Part A: Polym. Chem. 2004, 42, 5301-5338.

(29) Lub, J.; Broer, D. J.; Van Den Broek, N. Liebigs Ann. 1997, 22812288.

(30) Lub, J.; Broer, D. J.; Martinez Antonio, M. E.; Mol, G. N. Liq. Cryst. 1998, 24, 375-379.

(31) Lub, J.; Broer, D. J.; Allan, J. F. Mol. Cryst. Liq. Cryst. 1999, 332, 259-266.

(32) Wilderbeek, H. T. A.; Goossens, J. G. P.; Bastiaansen, C. W. M.; Broer, D. J. Macromolecules 2002, 35, 8962-8968.

(33) Wilderbeek, H. T. A.; Van Der Meer, M. G. M.; Jansen, M. A. G.; Nelissen, L.; Fischer, H. R.; Van Es, J. J. G. S.; Bastiaansen, C. W. M.; Lub, J.; Broer, D. J. Liq. Cryst. 2003, 30, 93-108. 


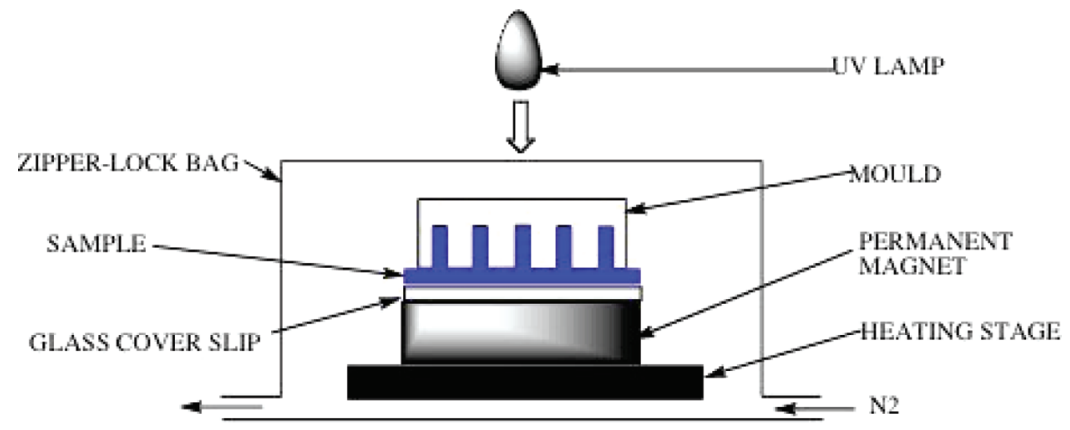

Figure 2. Experimental setup used to prepare the responsive pillars.

Both compounds presented a nematic mesophase. In particular, monomer 1 had a broad nematic mesophase (from 59 to 80 ${ }^{\circ} \mathrm{C}$ ), with an additional monotropic smectic A mesophase.

We first checked that the linear main-chain thiol-ene polymer obtained by polymerizing monomer $\mathbf{1}$ possessed the required nematic mesophase. Indeed, solution polymerization of monomer 1 in presence of a thermal radical initiator gave a nematic polymer with a nematic to isotropic phase transition around 170 ${ }^{\circ} \mathrm{C}$. (See Supporting Information for the detailed synthesis and characterization of compounds $\mathbf{1}$ and $\mathbf{2}$ as well as for the thiol-ene main-chain polymer.)

Then, using the setup described in Figure 2, the structured surfaces were prepared. A small amount of a mixture composed of the nematic monomer $\mathbf{1}(94.5 \mathrm{~mol} \%)$, the cross-linker 2 (5
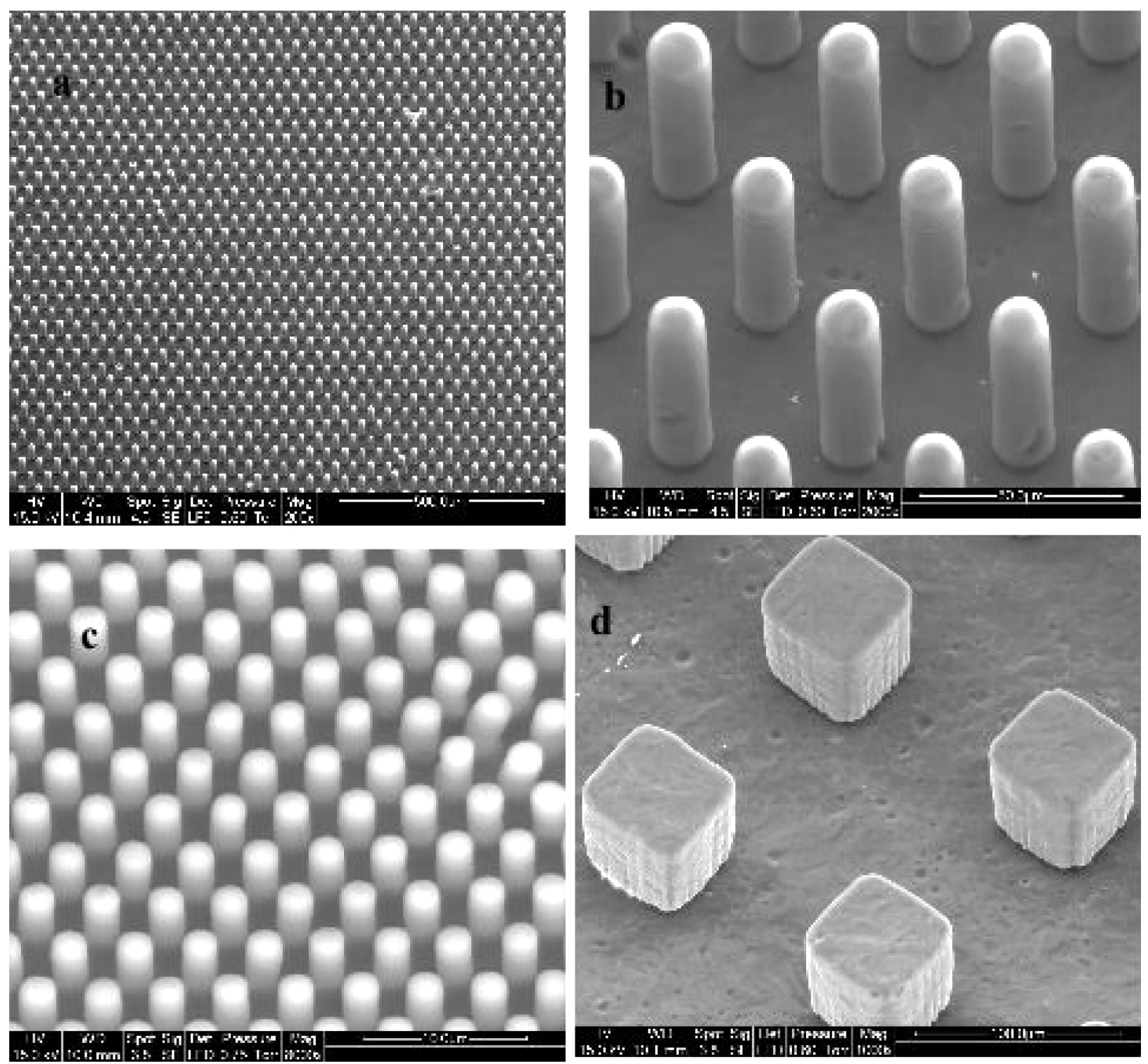

Figure 3. (a) and (b) SEM images shown at two magnifications of a surface covered with large cylindrical pillars; (c) SEM image of a surface covered with small cylindrical pillars; (d) SEM image of a surface covered with square pillars. 
mol \%) and the photoinitiator 2-benzyl-2-(dimethylamino)-4'morpholinobutyrophenone $(0.5 \mathrm{~mol} \%)$ was heated to its isotropic phase $\left(85^{\circ} \mathrm{C}\right)$ on a clean microscope coverslip positioned atop a rare earth permanent magnet $(\sim 1 \mathrm{~T} \mathrm{NdFeB}$ alloy (Aldrich)). A PDMS soft mold, prepared by replica molding, was then pressed down on the melted sample, which filled the inner structure of the mold. Four different molds were used, with various hole shapes and sizes.

The temperature was slowly decreased $\left(-0.5^{\circ} \mathrm{C} / \mathrm{min}\right)$ down to $70{ }^{\circ} \mathrm{C}$ to allow the formation of the nematic mesophase. During the slow cooling process, the applied magnetic field ensured the alignment of the nematic director parallel to the long axis of the pillars. The sample was then irradiated through the mold using a UV lamp $\left(30 \mathrm{~mW} \mathrm{~cm}^{-2}, \lambda=365 \mathrm{~nm}\right.$; ELC4001 light curing unit; Electro-Lite corporation) for $30 \mathrm{~min}$ to promote the photopolymerization of the monomer mixture. After cooling to room temperature, the PDMS mold was peeled off, leaving a thin glassy polymer film covered by a regular array of pillars, as seen by scanning electron microscopy (SEM) (Figure 3 and Figure SI-5 in Supporting Information).

To characterize their contraction, pillars were cut off the surface with a razor blade. When heated above the nematic to isotropic transition temperature (around $170{ }^{\circ} \mathrm{C}$ for the mainchain LCE), the pillars underwent an ultralarge contraction (Figure 4).

In the first stages of the contraction, the pillar kept its cylindrical shape (Figure $4 a, b$, and c), but at the end of the process, it reached the shape of "a coin" (Figure 4d). Furthermore, in some cases, this coin, being not able to stand on its "edge", flipped down on its "face" (Figure 4d, pillar on the right). On cooling down, the pillar returned to its original shape and size (Figure 4e).

Keeping in mind that the total volume of the elastomeric pillar (Poisson ratio $\approx 0.5$ ) remains nearly constant during the nematic to isotropic transition, one can then measure the thickness of the "edge" of the coin at full contraction and, as a consequence, calculate the contraction which could be estimated to reach 300-400\%.

The nematic main-chain LCE microactuators described here present contractions as large as the best macroscopic systems reported in the literature for mechanically oriented samples. ${ }^{20-26}$ Moreover, the observed contractions (up to 400\%) outperform the best values already reported for other LCE microsystems (ca. $40 \%)^{19,34-36}$

\section{Conclusion}

With these novel nematic main-chain LCE microactuators, we are one step closer to the responsive surfaces like the one drawn in Figure 1. One possible drawback for the system described here is its high nematic to isotropic transition and glass transition temperatures. However, high working temperatures could be considered an asset for development of a responsive polymer surface that could also be capable of shape memory. ${ }^{37}$ Using the considerable knowledge accumulated over the years in the liquid crystal field, the next step will be to design

(34) Elias, A. L.; Harris, K. D.; Bastiaansen, C. W. M.; Broer, D. J.; Brett, M. J. J. Mater. Chem. 2006, 16, 2903-2912.

(35) Van Oosten, C. L.; Harris, K. D.; Bastiaansen, C. W. M.; Broer, D. J. Eur. Phys. J. E 2007, 23, 329-336.

(36) Elias, A. L.; Brett, M. J.; Harris, K. D.; Bastiaansen, C. W. M.; Broer, D. J. Mol. Cryst. Liq. Cryst. 2007, 477, 137-151.

(37) Liu, C.; Qin, H.; Mather, P. T. J. Mater. Chem. 2007, 17, 1543-1558.

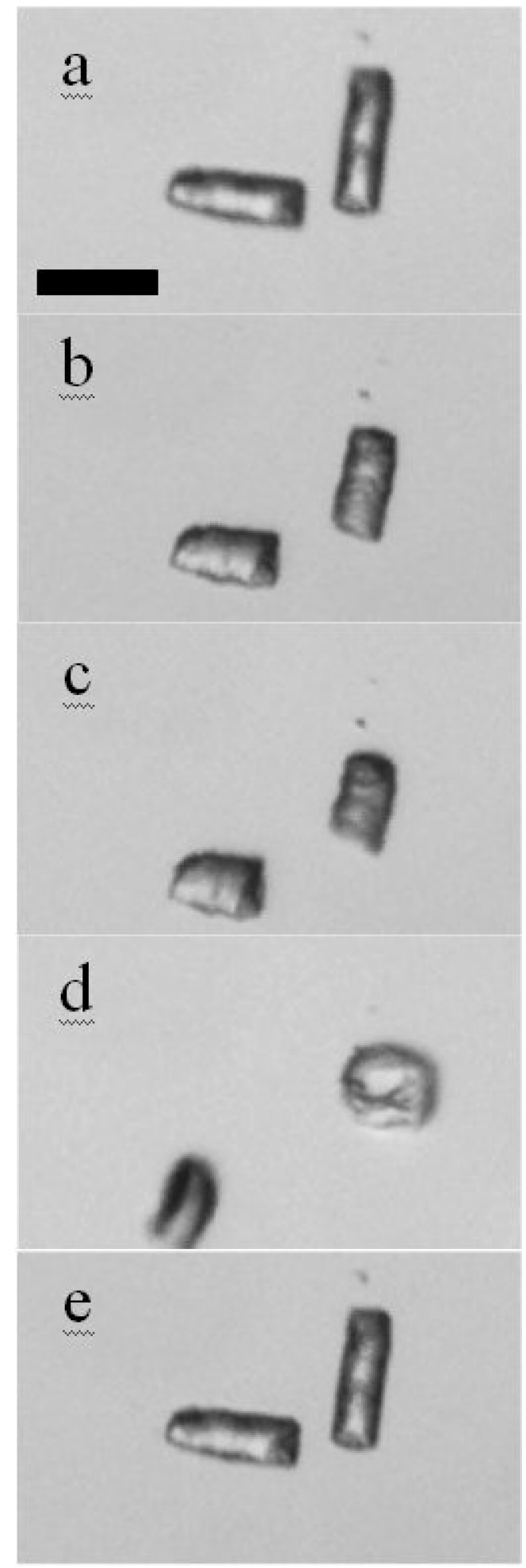

Figure 4. Contraction of isolated nematic main-chain LCE pillars heated up to the isotropic $(a-d)$, then cooled back to room temperature (e). Scale bare is $100 \mu \mathrm{m}$. A movie in AVI format shows this in motion.

new thiol-ene monomers and polymers with lower transition temperatures.

The straightforward method described here to prepare LCE microactuators with ultralarge contractions paves the way for the development of LCE-based responsive surfaces mimicking natural surfaces with specific properties. In addition, since the micrometer-sized actuators can be manipulated individually, they 
could be used in microfluidics as active elements to design micropumps or microvalves.

Our procedure could be easily extended to the preparation of azo main-chain LCE microactuators with photomechanical properties, using the photochemical approach we previously developed to prepare azo nematic side-on LCE films. ${ }^{38}$ Future work will address these goals.

Acknowledgment. This research was supported in part by the ANR (ANR-07-MAPR-0020)). We thank Dr. P. Silberzan (Curie

(38) Li, M.-H.; Keller, P.; Li, B.; Wang, X.; Brunet, M. Adv. Mater. 2003, $15,569-572$.
Institute) for the gift of the master used in the preparation of the small cylindrical pillars mold and Dr. J. Plastino (Curie Institute) and Dr. E. Tsai (University of Colorado at Boulder) for their critical reading of the manuscript.

Supporting Information Available: Experimental part S2, which presents the synthesis of monomer $\mathbf{1}$, cross-linker $\mathbf{2}$, and thiol-ene polymer, informations on the setup used to prepare the films and additional SEM pictures of the surfaces.

This material is available free of charge via the Internet at http://pubs.acs.org. 